Published in final edited form as:

Environ Res. 2014 July ; 132: 76-82. doi:10.1016/j.envres.2014.03.029.

\title{
Extracellular histones mediate the effects of metal-rich air particles on blood coagulation
}

\author{
L. Cantone ${ }^{\mathrm{a}}$, L. Angelici ${ }^{\mathrm{a}}$, V. Bollati ${ }^{\mathrm{a}}$, M. Bonzini ${ }^{\mathrm{b}}$, P. Apostoli ${ }^{\mathrm{c}}$, A. Tripodi $^{\mathrm{d}}$, P.A. Bertazzi ${ }^{\mathrm{a}}$, \\ and A.A. Baccarellie, ${ }^{*}$ \\ ${ }^{a}$ Center of Molecular and Genetic Epidemiology, Department of Clinical Sciences and \\ Community, Università di Milano and Fondazione Cà Granda, IRCCS Ospedale Maggiore \\ Policlinico, Milan, Italy \\ ${ }^{b}$ Department of Clinical and Experimental Medicine, University of Insubria, Varese, Italy \\ 'Occupational Medicine and Industrial Hygiene, University of Brescia, Department of \\ Experimental and Applied Medicine, Brescia, Italy \\ ${ }^{\mathrm{d} A n g e l o}$ Bianchi-Bonomi Haemophilia and Thrombosis Centre, Department of Medicine and \\ Medical Specialties, IRCCS Maggiore Hospital, Mangiagalli and Regina Elena Foundation, Milan, \\ Italy \\ eLaboratory of Environmental Epigenetics, Department of Environmental Health, Harvard School \\ of Public Health, Boston, MA, USA
}

\begin{abstract}
Background-Epidemiological studies have shown associations of particulate matter (PM) exposure with hypercoagulability and thrombosis. Extracellular circulating histones have recently been identified as novel mediators of inflammatory and procoagulant responses. The potential roles of extracellular histones in PM-related hypercoagulability have yet not been investigated.

Objectives-In 63 steel workers, we evaluated the effects of exposure to PM and PM metal components on two extracellular histone modifications (H3K4me3 and H3K9ac); and the association of $\mathrm{H} 3 \mathrm{~K} 4 \mathrm{me} 3$ and $\mathrm{H} 3 \mathrm{~K} 9 \mathrm{ac}$ with coagulation markers.
\end{abstract}

Methods-Extracellular H3K4me3 and H3K9ac were determined in plasma through enzymelinked immunosorbent assays. Coagulation markers included endogenous thrombin potentials (ETPs), tissue-type plasminogen activator antigen (t-PA) and $\mathrm{b}$-dimer. Exposure to PM with aerodynamic diameters $<1 \mu \mathrm{m}\left(\mathrm{PM}_{1}\right)$ or $<10 \mu \mathrm{m}\left(\mathrm{PM}_{10}\right)$ and $\mathrm{PM}_{10}$ metal components were estimated for each participant.

Results-The coagulation marker ETP, measured in the presence of soluble thrombomodulin (ETP TM+), showed significant positive associations with $\mathrm{PM}_{1}(\beta=107.84, p=0.03), \mathrm{PM}_{10}$ $(\beta=83.06, p=0.02)$, and zinc $(\beta=75.14, p=0.03)$; and a marginal association with iron $(\beta=122.58$,

(C) 2014 Elsevier Inc. All rights reserved.

"Correspondence to: Harvard School of Public Health, Landmark Center, Rm 415E West, PO-Box 15677, 401 Park Dr, Boston, MA 02215, USA. Fax: +617 384 8859. abaccare@ @sph.harvard.edu (A.A. Baccarelli).

None of the authors have relevant conflicts of interest. 
$p=0.07)$. Additional PM effects were observed on t-PA, D-dimer, and ETP TM+. PM 1 exposure was associated with increased plasma $\mathrm{H} 3 \mathrm{~K} 4 \mathrm{me} 3$ and $\mathrm{H} 3 \mathrm{~K} 9 \mathrm{ac}(\beta=0.20, p=0.02 ; \beta=0.16, p=0.05$, respectively). $\mathrm{H} 3 \mathrm{~K} 4 \mathrm{me} 3$, but not $\mathrm{H} 3 \mathrm{~K} 9 \mathrm{ac}$, was associated with zinc $(\beta=0.13, p=0.03)$ and iron $(\beta=0.32, p=0.01)$ contained in PM. ETP TM+ was increased in association with higher plasma H3K4me3 $(\beta=0.50, p=0.05)$ and H3K9ac $(\beta=0.54, p=0.05)$.

Conclusions-This observational study suggests potential roles of extracellular histones in PMinduced hypercoagulability. Experimental studies are warranted to further characterize these findings.

\section{Keywords}

Histones; Blood coagulation; Thrombosis; Particulate matter; Metals

\section{Introduction}

Epidemiology investigations have repeatedly linked environmental exposure to particulate matter (PM) with increased incidence and mortality from myocardial infarction (D'ippoliti et al., 2003) and ischemic stroke (O'donnell et al., 2011). Recent studies also suggest a relationship between PM exposure and risk of venous thrombosis (Baccarelli et al., 2008; Dales et al., 2010). The mechanisms linking inhalation of air particles to cardiovascular disease exacerbation are not completely understood (Brook et al., 2010). The aerodynamic diameter of air particles is critical to determine their health effects as shape and size are primary determinants of where inhaled particles are deposited throughout the respiratory tract (Brook et al., 2010). Fine particles $\left(\mathrm{PM}_{1}\right)$, but not larger particles, can reach the alveolar epithelium and cross over into the bloodstream, thus enhancing systemic inflammation (Ljungman, 2009). The roles of finer particles in determining cardiovascular effects have been pointed out by several epidemiological studies (Brook et al., 2010). PM components, as well as metals with strong pro-inflammatory actions, have been also shown to play key roles in determining PM-related cardiovascular effects (Zhang et al., 2009). PMinduced systemic inflammation has been suggested as a primary mediator of PM effects (Seaton et al., 1995; Ghio et al., 2003; Baccarelli et al., 2007). Finally, Bonzini et al. (2010) have recently shown that PM exposure is associated with increased coagulation activity, as reflected in shorter prothrombin time (PT), increased endogenous thrombin generation measured in the presence of soluble thrombomodulin (ETP TM+) - and higher tissue-type plasminogen activator antigen (t-PA).

Work conditions may cause exposures to indoor PM considerably higher than outdoor concentrations. In modern steel plants, workers are still exposed to inhalable PM at levels well above concentrations found in ambient outdoor air, which also contain a large proportion of potentially toxic metal components (Alley et al., 2009; Fang et al., 2009). In epidemiological studies, steel workers have been found at higher risk for cardiovascular disease (Andjelkovich et al., 1990). Several metals have been demonstrated to have procoagulant effects; iron and zinc, the two metals usually found at highest concentrations in foundry PM, have been shown to have the greatest toxicity (Arslan et al., 2010; Sangani et al., 2010). Several prothrombotic modifications have been described after exposure to iron and zinc, such as alteration of clotting factors activity, increased platelet aggregation, 
reduced clotting time, and higher expression of pro-coagulant genes and proteins (Gilmour et al., 2006). Treatment with intravenous iron can be complicated by venous thrombosis (Seftel, 1965) and iron over-dose can cause coagulopathy (Cheney et al., 1995).

Histones are nuclear proteins which organize themselves into nucleosomes containing two copies each of the core histones $\mathrm{H} 2 \mathrm{~A}, \mathrm{H} 2 \mathrm{~B}, \mathrm{H} 3$, and $\mathrm{H} 4$, in addition to the DNA wrapped around the histone octamer. Nucleosomes can be released in the extracellular matrix during apoptosis or can be actively secreted by inflammatory cells (Jahr et al., 2001). A recent study demonstrated that histones $\mathrm{H} 3$ and $\mathrm{H} 4$ are increased and mediate pro-inflammatory signaling in plasma samples from human individuals with sepsis, a condition associated with subclinical activation of blood coagulation (Semeraro et al., 2010). Extracellular histones also have strong affinity for circulating fibrinogen and prothrombin, which precipitate following the addition of histones, thus triggering clot formation (Fuchs et al., 2010; Pemberton et al., 2010). Recently, Ammollo et al. (2011) demonstrated that histones induce plasma thrombin production by reducing thrombomodulin-dependent protein $\mathrm{C}$ activation. Taken together, these findings indicate histones as emerging bridging molecules with biological significance for coagulation (Pemberton et al., 2010).

Deligezer et al. (2008) have recently shown specific posttranslational modifications in plasma samples that were independent of the amounts of circulating nucleosomes. The presence of specific histone modifications in plasma has been suggested to contribute to selective activation of immune pathways and inflammatory responses (Dieker et al., 2007). In the same population of steel workers investigated in the present work, we have previously reported alterations of histone modifications (H3 Lysine 4 trimethylated [H3K4me3] and H3 Lysine 9 acetylated [H3K9ac]) in blood leukocytes following long-term PM exposure and related with specific PM metal-component levels (Cantone et al., 2011). Growing evidence suggests that extracellular histones may influence coagulation due to their strong tendency to form aggregates and precipitate with plasma proteins (Pemberton et al., 2010). In particular, histone aggregation with fibrinogen and prothrombin may enhance the effects of procoagulant factors on blood clotting (Fuchs et al., 2010; Semeraro et al., 2010; Ammollo et al., 2011). However, whether PM exposure induces changes in extracellular circulating histones, and whether extracellular histones are linked to disease-related biological outcomes has not yet been evaluated.

In the present study on steel workers with a wide range of exposure to PM, we investigated whether PM and metals in inhalable particles determined changes in two activating extracellular histone modifications - histone $\mathrm{H} 3 \mathrm{~K} 4 \mathrm{me} 3$ and $\mathrm{H} 3 \mathrm{~K} 9 \mathrm{ac}$ - in plasma. We also evaluated whether the observed modifications in extracellular histones were correlated with blood coagulation function.

\section{Materials and methods}

\subsection{Study participants and exposure assessment}

We investigated 63 male healthy workers, free of cancer and cardiopulmonary disease, who had been working in a steel production plant in Brescia, Northern Italy for at least one year. Individual written informed consent and approval from the local Institutional Review Board 
were obtained before the study. The study subjects worked in 11 different areas within the plant, which were selected to provide a wide contrast of exposures between the study participants. The exposure of each of the study participants in the plant was monitored for the first three working days of a work week. We obtained blood samples for coagulation and other biomarker measurements at two different times: time 1, in the morning of the first day of the workweek (following two days off work) before the beginning of any work activity; time 2 , in the morning of the fourth day of the same workweek, following three consecutive days of work.

We used EDTA tubes to collect $7 \mathrm{~mL}$ whole blood that was promptly (within $30 \mathrm{~min}$ ) centrifuged on site at $2500 \mathrm{rpm}$ for $15 \mathrm{~min}$. A whole blood aliquot $(300 \mu \mathrm{L})$ was used for a complete blood count with differential. A plasma aliquot $(200 \mu \mathrm{L})$ was separated and transferred in a cryovial, immediately stored at $-80^{\circ} \mathrm{C}$ until use. A self-administered questionnaire was used to collect detailed information on smoking habits, drug use (including NSAID), medical conditions, Body Mass Index (BMI) and education. Personal exposures during the working particle mass (PM with aerodynamic diameters $<1 \mu \mathrm{m}\left[\mathrm{PM}_{1}\right]$ and $<10 \mu \mathrm{m}\left[\mathrm{PM}_{10}\right]$ ) and particle metal components (aluminum, manganese, nickel, zinc, arsenic, lead, iron) were estimated as previously described (Bonzini et al., 2010). In the plant, exposure levels have shown very little variability over time, as measures repeated over three years in a subset of the study population showed very high correlations $\left(r^{2}>0.90\right)$. Therefore, the time-weighted levels of metals and particles represented, in addition to the exposure during the week of the study, also a measure of the usual exposure of the study participants (Tarantini et al., 2009).

\subsection{Coagulation tests}

We collected peripheral blood for coagulation testing into vacuum tubes (Becton Dickinson, Meylan, France) with $0.109 \mathrm{M}$ trisodium citrate at a 9:1 blood/anticoagulant ratio. We determined t-PA and the fibrin degradation product that contains two cross-linked D fragments of the fibrin protein (D-dimer) using commercially available enzyme-linked immunosorbent assay (ELISA) kits (ELISA-Zymutest; HYPHEN BioMed, Neuville-SurOise, France). According to Hemker et al. (2003), as described by Chantarangkul et al. (2003), we assessed thrombin generation potential (ETP) as a global measure of coagulation activation. The test was based on the activation of coagulation in platelet poor plasma with calcium chloride. We performed the test in the presence and in absence of soluble rabbit thrombomodulin (ETP TM+ and ETP TM- respectively) (ICN Biomedicals, Aurora, OH, USA) as activator of protein $\mathrm{C}$, added to the reaction mixture at a final concentration of 4 $\mathrm{nM}$. Continuous registration of the generated thrombin was achieved with a fluorogenic synthetic substrate (Z-Gly-Gly-Arg-AMC-HCl; Bachem, AG, Bubendorf, Switzerland) added to the test system at a final concentration of $417 \mu \mathrm{M}$. The procedure was carried out with an automated fluorometer (Fluoroskan Ascent; ThermoLabsystem, Helsinki, Finland). We automatically recorded readings from the fluorometer and analyzed results with dedicated software (THROMBINO-SCOPE; Thrombinoscope BV, Maastricht, The Netherlands), which displays thrombin generation curves [nM thrombin vs. time (min)] and calculates the area under the curve. ETP represents the plasma balance between procoagulants and anticoagulants agents. 


\subsection{Histone modification analysis}

In each run, $20 \mu \mathrm{L}$ of plasma was analyzed by solid-phase sandwich enzyme-linked immunosorbent assay (ELISA), using monoclonal antibodies to detect H3K4me3 acetylated H3K9ac (EpiQuik Assay Kit, Epigentek, Brooklyn, NY, USA) (Deligezer et al., 2010). We used a Synergy HT-BioTek spectrophotometer to read $490 \mathrm{~nm}$ absorbance (OD), which was assumed proportional to the concentration of modified histones (Deligezer et al., 2010). The reliability coefficient of single ELISA runs was 0.93 (95\% CI: 0.89-0.96) for H3K9 acetylation and 0.85 (95\% CI: 0.77-0.92) for H3K4 trymetylation. Therefore, every sample was tested two times for each assay to increase reliability. The average of the two runs was used in the statistical analysis.

\subsection{Statistical analysis}

H3K4me3 and H3K9ac did not show significant differences between time 1 and time 2 (mean of $0.05 \mathrm{OD}$ for time 1, and $0.05 \mathrm{OD}$ for time 2, $p$-value $=0.59$ for $\mathrm{H} 3 \mathrm{~K} 4 \mathrm{me} 3$; and mean $0.05 \mathrm{OD}$ for time 1 , and $0.07 \mathrm{OD}$ for time $2, p$-value $=0.28$ for H3K9ac). Therefore, we evaluated the level of individual exposure to PM and PM components, taken as a measure of usual personal levels of exposure, regardless of whether histone markers were measured on samples taken on the first day of work (time 1), or after three consecutive days of work (time 2). We fitted statistical models on data that included the two repeated measures of histone modifications $\mathrm{H} 3 \mathrm{~K} 4 \mathrm{me} 3$ and $\mathrm{H} 3 \mathrm{~K} 9 \mathrm{ac}$ in both simple regression models and multiple regression models adjusted for age, BMI, education, current smoking status (Yes/No), and percent granulocytes.

The association of PM metal components and PM mass levels with histone modifications H3K4me3 and H3K9ac was analyzed using simple and multiple linear regression models. The multiple regression models were adjusted for age, BMI (continuous variables), current smoking status (Yes/No) and education (categorical variables). In addition, we adjusted for percent granulocytes - the major cell type in blood leukocytes - in the differential blood count to account for the confounding effect of possible differences in the proportion of leukocyte subtypes associated with the exposures.

We then evaluated the association of histone modifications with coagulation and inflammatory markers, i.e. t-PA, and $\mathrm{D}$-dimer, ETP TM+, and, finally we evaluated the effects on the same markers of PM mass and PM metal components. We fitted simple and multiple linear regression models adjusted for age, BMI, education, current smoking (Yes/ No), and NSAIDs.

To compare the magnitude of the associations of H3K4me3 and H3K9ac with different exposures and blood coagulation markers, we calculated standardized regression coefficients $\left(\beta_{s t d}\right)$ and $95 \%$ confidence intervals (CIs) that express the change in histone modifications associated with an increase in exposure equal to the difference between the 90th and 10th percentile of the exposure distribution. We checked regression assumptions by performing diagnostic tests for each model, which included the Shapiro-Wilk test to verify normality of residuals and the White test to verify the homogeneity of variance of the residuals. A two- 
sided $p$-value $<0.05$ was considered statistically significant. Statistical analyses were performed in SAS (version 9.1.3; SAS Institute Inc., Cary, NC, USA).

\section{Results}

\subsection{Participants' characteristics and exposure levels}

The mean age of the 63 enrolled workers was 44 years (range 27-55 years). Twenty-five subjects $(40 \%)$ were current smokers and reported a median number of 15 cigarettes smoked every day (range 1-30). The median BMI of the study participants was $26.5 \mathrm{~kg} / \mathrm{m}^{2}$

$(\mathrm{SD}=2.7)$. For both metal levels and PM mass, the study participants showed wide ranges of exposures (Table 1), reflecting their placement in different work areas in the plant.

\subsection{Effects of PM and metal components on coagulation markers}

In multiple covariate-adjusted regression models, we found a positive significant association of ETP TM+ with $\mathrm{PM}_{1}(\beta=107.8,95 \% \mathrm{CI}: 12.5 ; 203.2 p=0.03), \mathrm{PM}_{10}(\beta=83.1,95 \% \mathrm{CI}: 10.8$; $155.3 p=0.02)$ and zinc $(\beta=75.1,95 \%$ CI: $6.3 ; 143.9 p=0.03)$ levels (Table 2$)$. ETP TM showed a positive significant association with zinc ( $\beta=97.6,95 \% \mathrm{CI}:-1.7 ; 197.0 p=0.05)$ and iron $(\beta=233.8,95 \% \mathrm{CI}:-46.7 ; 420.8 p=0.01)$. t-PA was significantly associated with nickel $(\beta=-1.93,95 \% \mathrm{CI}:-3.77 ;-0.1 p=0.04)$, zinc $(\beta=-1.30,95 \% \mathrm{CI}:-2.17 ;-0.44 p=0.001)$ and iron $(\beta=-3.24,95 \% \mathrm{CI}: 4.82 ;-1.66 p=0.001)$ levels. Also D-dimer showed an association with zinc $(\beta=-18.9,95 \% \mathrm{CI}:-37.4 ;-0.4 p=0.05)$ exposure.

\subsection{Effects of PM and metal components on extracellular plasma histone modifications}

In unadjusted models, $\mathrm{H} 3 \mathrm{~K} 4 \mathrm{me} 3$ was significantly associated with zinc $\left(\beta_{s t d}=0.13,95 \% \mathrm{CI}\right.$ : $0.01 ; 0.25, p=0.03)$ and iron exposure levels $\left(\beta_{s t d}=0.27,95 \% \mathrm{CI}: 0.05 ; 0.50 p=0.02\right)$. H3K9ac was significantly associated with $\mathrm{PM}_{1}\left(\beta_{s t d}=0.16\right.$, 95\%CI: $\left.0.01 ; 0.31 p=0.04\right)$ (Table 3$)$. Adjusted multiple regression models showed a significant positive association of $\mathrm{H} 3 \mathrm{~K} 4 \mathrm{me} 3$ with $\mathrm{PM}_{1}\left(\beta_{\text {std }}=0.20,95 \% \mathrm{CI}\right.$ : 0.03; $\left.0.36 p=0.02\right)$ and confirmed the associations found in unadjusted models with zinc $\left(\beta_{s t d}=0.13,95 \% \mathrm{CI}\right.$ : $\left.0.001 ; 0.25 p=0.03\right)$ and iron $\left(\beta_{\text {std }}=0.32\right.$, 95\%CI: $0.10 ; 0.54 p=0.01)$. Also, adjusted multiple regression models confirmed the association of $\mathrm{H} 3 \mathrm{~K} 9 \mathrm{ac}$ with $\mathrm{PM}_{1}$ exposure levels $\left(\beta_{s t d}=0.16,95 \% \mathrm{CI}\right.$ : $\left.0.00 ; 0.32 p=0.05\right)$.

\subsection{Correlation of extracellular plasma modifications with coagulation markers}

Unadjusted models showed that $\mathrm{H} 3 \mathrm{~K} 4 \mathrm{me} 3$ had a significant positive association with ETP $\mathrm{TM}+\left(\beta_{s t d}=0.55,95 \% \mathrm{CI}: 0.08 ; 1.01 p=0.02\right)$, and a significant negative association with t-PA $\left(\beta_{s t d}=-0.60,95 \% \mathrm{CI}:-1.04 ;-0.16 p=0.01\right)$. H3K9ac also showed similar significant associations with ETP TM+ $\left(\beta_{s t d}=0.47,95 \% \mathrm{CI}: 0.01 ; 0.94 p=0.05\right)$ and $\mathrm{t}-\mathrm{PA}\left(\beta_{\text {std }}=-0.48\right.$, 95\%CI: $-0.92 ;-0.03 p=0.04$ ) (Table 4 ). Adjusted multiple regression models confirmed the significant association between $\mathrm{H} 3 \mathrm{~K} 4 \mathrm{me} 3$ and ETP TM+ $\left(\beta_{\text {std }}=0.50,95 \% \mathrm{CI}\right.$ : $-0.01 ; 1.01$ $p=0.05)$ and showed a borderline negative association between $\mathrm{H} 3 \mathrm{~K} 4 \mathrm{me} 3$ and t-PA $\left(\beta_{s t d}=0.36,95 \% \mathrm{CI}:-0.77 ; 0.04 p=0.08\right)$; also, H3K9ac showed again the significant associations with ETP TM+ $\left(\beta_{s t d}=0.54,95 \% \mathrm{CI}: 0.01 ; 1.08 p=0.05\right)$, whereas its association with t-PA did not reach statistical significance in this set of adjusted models $\left(\beta_{s t d}=-0.34\right.$, 95\%CI: -0.77 ; $0.08 p=0.11)$. 


\section{Discussion}

The present study on a population of healthy steel workers with well-characterized exposure to a wide range of metal-rich PM levels showed exposure-related increases in extracellular plasma histone modifications $\mathrm{H} 3 \mathrm{~K} 4 \mathrm{me} 3$ and $\mathrm{H} 3 \mathrm{~K} 9 \mathrm{ac}$, as well as associations of extracellular histones $\mathrm{H} 3 \mathrm{~K} 4 \mathrm{me} 3$ and $\mathrm{H} 3 \mathrm{~K} 9 \mathrm{ac}$ with coagulation biomarkers, such as ETP TM + and t-PA.

To the best of our knowledge this is the first study evaluating effects of PM exposures on extracellular plasma histone modifications in human individuals. We also consistently linked the exposure-related differences in plasma histone modifications with clinical coagulation biomarkers, most consistently with ETP TM+. Recent studies have linked extracellular histones with changes in coagulation-related biomarkers such as thrombomodulin, platelet aggregation, and LDL aggregation (Pemberton et al., 2010; Semeraro et al., 2010; Ammollo et al., 2011). Extracellular histones have a strong tendency to form aggregates and precipitate with plasma proteins, in particular with fibrinogen and prothrombin, thus enhancing stimulus for blood clotting (Fuchs et al., 2010; Pemberton et al., 2010). These previous findings demonstrate roles of extracellular histones in coagulation activation that are consistent with our study findings.

Wu et al. (2012) have recently shown in mice treated with Sirt1 - a member of histone deacetylases - decreased histone acetylation, reduced lung inflammation, and decreased coagulation following PM exposure. On the contrary, knock-out Sirt1 mice showed enhanced thrombosis and inflammation. Histone acetylation is expected to generally increase DNA accessibility and gene expression. In the present study, we also analyzed two permissive histone marks with high frequency of occurrence (Hung et al., 2009; Cantone et al., 2011). We found that extracellular H3K4me3 and H3K9ac were positively correlated with $\mathrm{PM}_{1}$, zinc and iron, as well as with ETP TM+ and tPA, suggesting a key role of extracellular histone modifications in promoting PM-related hypercoagulability. Our results show for the first time in a human population exposure-related differences of histone marks in the extracellular plasma compartment. The correlations of plasma H3K4me3 and H3K9ac modifications with clinical biomarkers of coagulation are highly consistent with their suggested roles as activators of blood coagulation.

Metals contained in PM have been linked to cardiovascular diseases in animal (Corey et al., 2006) and human studies (Chen and Lippmann, 2009). Treatment with water-soluble fraction of PM significantly accelerated whole blood coagulation time in vitro (Sangani et al., 2010). Zinc is a metal with remarkable procoagulant effect (Gilmour et al., 2006; Sangani et al., 2010; Tarantini et al., 2013). Zinc is a common constituent of ambient PM and a workplace toxin that can lead to functional changes in the lung and subsequent systemic inflammation and cardiovascular alterations in humans (Fine et al., 1997). Animal rat models have demonstrated systemic inflammation and procoagulant effects following pulmonary zinc exposure (Gilmour et al., 2006).

Recently, iron has also been described as novel marker of enhancement of fibrin formation. Iron alters fibrinogen molecules thus promoting polymerization of fibrin monomers with 
thrombin. Iron significantly accelerates the coagulation of whole native blood and inhibits its spontaneous fibrinolysis (Lipinski et al., 2012).

We observed stronger effect for $\mathrm{PM}_{1}$, but not coarse particles, probably because fine particles can reach the alveolar epithelium and cross over into the bloodstream (Ljungman, 2009) and directly interact with the blood or other tissues.

ETP is a global functional assay that describes overall coagulability and represents the time course of formation and decay of thrombin, the key enzyme in clot formation in response to triggering by tissue factor (Siegemund et al., 2004). Thrombin generation decreases in patients treated with anticoagulants (Kakkar et al., 2002), increases in patients with thrombophilia (Wielders et al., 1997), and has been recently correlated with higher risk of venous thromboembolism (Tripodi et al., 2007). Increased ETP was associated with PM concentrations when the assay was performed in the presence, but not in the absence of thrombomodulin. Thrombomodulin is the main physiological activator of protein $\mathrm{C}$ and its addition makes the assay able to mimic much more closely in-vivo conditions (Ammollo et al., 2011). Thus, our finding specifically suggests that PM exposure makes plasma resistant to the action of thrombomodulin as a protein $\mathrm{C}$ activator.

We also found a decrease of t-PA in association with histone modifications H3K4me3 and $\mathrm{H} 3 \mathrm{~K} 9 \mathrm{ac}$ as well as a significant association between $\mathrm{H} 3 \mathrm{~K} 4 \mathrm{me} 3$ and zinc exposure. A decrease of t-PA antigen is correlated with decreased fibrinolytic activity and clot solution through inhibition of the degradation of cross-linked fibrin, ultimately resulting in the promotion of thrombosis (Gilmour et al., 2006). Gilmour et al. (2006) demonstrated that exposure to zinc increases circulating plasminogen activator inhibitor-1 (PAI-1), a wellknown inhibitor of t-PA in fibrinolysis, and increases plasma fibrinogen. In this context, the results of the present study identify $\mathrm{H} 3 \mathrm{~K} 4 \mathrm{me} 3$ as a possible molecular mechanism of the effects of zinc exposure on t-PA.

We modeled our data by including in repeated-measure models both measurements taken before (time 1) and after (time 2) three consecutive working days (Bonzini et al., 2010). In these models, the effects on the two time points were assumed to be similar (Tarantini et al., 2009). This observation, coupled with the finding of no differences between the first and last day of the same working week, suggests that the air particles operate on extracellular histone modifications and coagulation markers over an extended timeframe, possibly producing a persistent alterations that are not reset to baseline over the 2 days off between consecutive working weeks. Because of the limited number of study subjects, it is possible that the observed associations were due to chance. However, our findings show internal coherence, as well as consistency with previous experimental and observational data. Also, the wide ranges of exposures and relatively controlled environment in the foundry were well-suited for evaluating effects on extracellular histones, while reducing bias and chance findings (Bollati et al., 2010). Furthermore, while we used multivariable models to control for potential confounders, we cannot exclude residual confounding from measured and unmeasured variables, including but not limited to different dietary patterns or common activities conducted during off hours. 
The study participants showed a wide range of exposure levels, owing to the differences in PM levels in the different job positions across the work facility. The differences in the individual levels of exposure in our study group were large $\left(\right.$ range $\left.=73-1220 \mu \mathrm{g} / \mathrm{m}^{3}\right)$ and provided sufficient contrast for identifying exposure-related changes in histone modifications and coagulation markers. A major advantage of our approach is that we could obtain a large contrast in exposures without including an external reference population of individuals working outside the steel factory. In studies of occupational groups, inclusion of referents working in a different workplace has been demonstrated to have high potential for bias due to differences in personal characteristics determining hiring into the different types of jobs, such as for instance socioeconomic factors of physical constitution (Pearce et al., 2007).

This investigation is an observational study including human volunteers occupationally exposed to a mix of metal rich particles in real-life condition. Experimental studies, involving in vitro and/or animal experiments, are needed to further expand our observations, which have limited capability to answer mechanistic questions. Also, the analytical methods used in our study directly measured the total quantities of modified histones, but did not provide information on the proportions of modified histones among all circulating histones. This limited our capability to determine the ratio of histone modifications to total circulating histones and nucleosomes.

We analyzed metals in $\mathrm{PM}_{10}$ to optimize analytical precision, which was enhanced due to the high amounts of particle mass that can be collected for $\mathrm{PM}_{10}$. Regrettably, because $\mathrm{PM}_{1}$ components were not analyzed, a complete comparison between the metals contained in $\mathrm{PM}_{10}$ particles and $\mathrm{PM}_{1}$ is not possible in this study. Different relative concentrations of metals in coarse and fine particles may account for the differential associations of $\mathrm{PM}_{1}$ and $\mathrm{PM}_{10}$ with the outcomes evaluated.

Although foundry workers in our study were in a modern facility with state-of-art systems for exposure reduction, we cannot exclude that exposures other than PM and metals, such as heat, carbon monoxide, and non-ionizing radiations (Lewis et al., 1992; Gomes et al., 2002) might have contributed to the observed effects (Tarantini et al., 2009; Cantone et al., 2011). In light these limitations, our results must be interpreted with caution.

In summary, our findings indicate that metal rich air particles modify the levels of specific extracellular histone modifications. Histone modications were correlated with specific coagulation markers. In particular, $\mathrm{PM}_{1}$, zinc and iron were correlated with increased extracellular H3K4 trimethylation and $\mathrm{H} 3 \mathrm{~K} 9$ acetylation in plasma. Future mechanistic studies are warranted to characterize the roles of plasma histone modifications in the pathways mediating the blood procoagulant effects of PM and further elucidate the findings of this observational study

\section{Acknowledgments}

Cantone L. and Baccarelli A.A. developed concept and design, interpretation of data, writing or critical revision of the intellectual content, and final approval of the version to be published; Angelici L. provided assistance for statistical analysis and/or interpretation of data, writing or critical revision of the intellectual content; Bonzini M. was involved in writing or critical revision of the intellectual content; Bollati V., Bertazzi P.A., Apostoli P. and 
Tripodi A. were involved in interpretation of data, critical revision of the intellectual content. All of the authors approved the final version of the article.

Funding sources

This work was supported by 'Dote Ricerca': FSE, Regione Lombardia, ESSIA Regione Lombardia DGR VIII/ 10462 and PRIN-2007-2-S2 HT8. Dr. Baccarelli received support from the HSPH-NIEHS Environmental Health Center (ES000002) and NIEHS R21-ES020984.

Human subjects

This research project was approved by the 'Maggiore Policlinico Hospital, Mangiagalli and Regina Elena Foundation' Institutional Review Board and the participants gave their informed consent.

\section{Abbreviations}

$\begin{array}{ll}\text { BMI } & \begin{array}{l}\text { body mass index } \\ \text { ETP TM+/ETP TM- }\end{array} \\ \text { endogenous thrombin generation-in the presence/absence of } \\ \text { soluble thrombomodulin } \\ \text { ELISA } & \text { endogenous thrombin potential } \\ \text { H3K4me3 } & \text { H3 Lysine } 4 \text { trimethylated } \\ \text { H3K9ac } & \text { H3 Lysine } 9 \text { acetylated } \\ \text { PM } & \text { particulate matter } \\ \text { PM1 } & \text { particulate matter with aerodynamic diameters }<1 \mu \mathrm{m} \\ \text { PM10 } & \text { particulate matter with aerodynamic diameters }<10 \mu \mathrm{m} \\ \text { PAI-1 } & \text { plasminogen activator inhibitor-1 } \\ \text { t-PA } & \text { tissue-type plasminogen activator } \\ \text { TM } & \text { thrombomodulin }\end{array}$

\section{References}

Alley D, Langley-Turnbaugh S, Gordon N, Wise J, Van Epps G, Jalbert A. The effect of PM 10 on human lung fibroblasts. Toxicol. Ind. Health. 2009; 25:111-120. [PubMed: 19458133]

Ammollo CT, Semeraro F, Xu J, Esmon NL, Esmon CT. Extracellular histones increase plasma thrombin generation by impairing TM-dependent protein C activation. J. Thromb. Haemost. 2011; 9:1795-1803. [PubMed: 21711444]

Andjelkovich DA, Mathew RM, Richardson RB, Levine RJ. Mortality of iron foundry workers: I. Overall findings. J. Occup. Med. 1990; 32:529-540. [PubMed: 2166148]

Arslan C, Altan H, Akgun OO, Kiziler AR, Aydemir B, Guzel S, Besirli K, Bozkurt AK. Trace elements and toxic heavy metals play a role in Buerger disease and atherosclerotic peripheral arterial occlusive disease. Int. Angiol. 2010; 29:489-495. [PubMed: 21173730]

Baccarelli A, Martinelli I, Zanobetti A, Grillo P, Hou LF, Bertazzi PA, Mannucci PM, Schwartz J. Exposure to particulate air pollution and risk of deep vein thrombosis. Arch. Intern. Med. 2008; 168:920-927. [PubMed: 18474755]

Baccarelli A, Zanobetti A, Martinelli I, Grillo P, Hou L, Giacomini S, Bonzini M, Lanzani G, Mannucci PM, Bertazzi PA, Schwartz J. Effects of exposure to air pollution on blood coagulation. J. Thromb. Haemost. 2007; 5:252-260. [PubMed: 17083648] 
Bollati V, Marinelli B, Apostoli P, Bonzini M, Nordio F, Hoxha M, Pegoraro V, Motta V, Tarantini L, Cantone L, Schwartz J, Bertazzi PA, Baccarelli A. Exposure to metal-rich particulate matter modifies the expression of candidate microRNAs in peripheral blood leukocytes. Environ. Health Perspect. 2010; 118:763-768. [PubMed: 20061215]

Bonzini M, Tripodi A, Artoni A, Tarantini L, Marinelli B, Bertazzi PA, Apostoli P, Baccarelli A. Effects of inhalable particulate matter on blood coagulation. J. Thromb. Haemost. 2010; 8:662-668. [PubMed: 19922434]

Brook RD, Rajagopalan S, Pope CA 3rd, Brook JR, Bhatnagar A, Diez-Roux AV, Holguin F, Hong Y, Luepker RV, Mittleman MA, Peters A, Siscovick D, Smith SC Jr, Whitsel L, Kaufman JD. Particulate matter air pollution and cardiovascular disease: an update to the scientific statement from the American Heart Association. Circulation. 2010; 121:2331-2378. [PubMed: 20458016]

Cantone L, Nordio F, Hou L, Apostoli P, Bonzini M, Tarantini L, Angelici L, Bollati V, Zanobetti A, Schwartz J, Bertazzi PA, Baccarelli A. Inhalable metal-rich air particles and histone H3K4 dimethylation and H3K9 acetylation in a cross-sectional study of steel workers. Environ. Health Perspect. 2011; 119:964-969. [PubMed: 21385672]

Chantarangkul V, Clerici M, Bressi C, Giesen PL, Tripodi A. Thrombin generation assessed as endogenous thrombin potential in patients with hyper- or hypo-coagulability. Haematologica. 2003; 88:547-554. [PubMed: 12745274]

Chen LC, Lippmann M. Effects of metals within ambient air particulate matter (PM) on human health. Inhalation Toxicol. 2009; 21:1-31.

Cheney K, Gumbiner C, Benson B, Tenenbein M. Survival after a severe iron poisoning treated with intermittent infusions of deferoxamine. J. Toxicol. Clin. Toxicol. 1995; 33:61-66. [PubMed: 7837315]

Corey LM, Baker C, Luchtel DL. Heart-rate variability in the apolipoprotein E knockout transgenic mouse following exposure to Seattle particulate matter. J. Toxicol. Environ. Health Part A. 2006; 69:953-965. [PubMed: 16728373]

D'ippoliti D, Forastiere F, Ancona C, Agabiti N, Fusco D, Michelozzi P, Perucci CA. Air pollution and myocardial infarction in Rome: a case-crossover analysis. Epidemiology. 2003; 14:528-535. [PubMed: 14501267]

Dales RE, Cakmak S, Vidal CB. Air pollution and hospitalization for venous thromboembolic disease in Chile. J. Thromb. Haemost. 2010; 8:669-674. [PubMed: 20088925]

Deligezer U, Akisik EE, Erten N, Dalay N. Sequence-specific histone methylation is detectable on circulating nucleosomes in plasma. Clin. Chem. 2008; 54:1125-1131. [PubMed: 18487283]

Deligezer U, Yaman F, Darendeliler E, Dizdar Y, Holdenrieder S, Kovancilar M, Dalay N. Posttreatment circulating plasma BMP6 mRNA and H3K27 methylation levels discriminate metastatic prostate cancer from localized disease. Clin. Chim. Acta. 2010; 411:1452-1456. [PubMed: 20573596]

Dieker JW, Fransen JH, Van Bavel CC, Briand JP, Jacobs CW, Muller S, Berden JH, Van Der Vlag J. Apoptosis-induced acetylation of histones is pathogenic in systemic lupus erythematosus. Arthritis Rheum. 2007; 56:1921-1933. [PubMed: 17530637]

Fang GC, Lin SJ, Lee JF, Chang CC. A study of particulates and metallic element concentrations in temple. Toxicol. Ind. Health. 2009; 25:93-100. [PubMed: 19458131]

Fine JM, Gordon T, Chen LC, Kinney P, Falcone G, Beckett WS. Metal fume fever: characterization of clinical and plasma IL-6 responses in controlled human exposures to zinc oxide fume at and below the threshold limit value. J. Occup. Environ. Med. 1997; 39:722-726. [PubMed: 9273875]

Fuchs TA, Brill A, Duerschmied D, Schatzberg D, Monestier M, Myers DD Jr, Wrobleski SK, Wakefield TW, Hartwig JH, Wagner DD. Extracellular DNA traps promote thrombosis. Proc. Nat. Acad. Sci. U.S.A. 2010; 107:15880-15885.

Ghio AJ, Hall A, Bassett MA, Cascio WE, Devlin RB. Exposure to concentrated ambient air particles alters hematologic indices in humans. Inhal. Toxicol. 2003; 15:1465-1478. [PubMed: 14648359]

Gilmour PS, Nyska A, Schladweiler MC, Mcgee JK, Wallenborn JG, Richards JH, Kodavanti UP. Cardiovascular and blood coagulative effects of pulmonary zinc exposure. Toxicol. Appl. Pharmacol. 2006; 211:41-52. [PubMed: 16005037] 
Gomes J, Lloyd O, Norman N. The health of the workers in a rapidly developing country: effects of occupational exposure to noise and heat. Occup. Med. (Lond). 2002; 52:121-128. [PubMed: 12063357]

Hemker HC, Giesen P, Al Dieri R, Regnault V, De Smedt E, Wagenvoord R, Lecompte T, Beguin S. Calibrated automated thrombin generation measurement in clotting plasma. Pathophysiol. Haemost. Thromb. 2003; 33:4-15. [PubMed: 12853707]

Hung T, Binda O, Champagne KS, Kuo AJ, Johnson K, Chang HY, Simon MD, Kutateladze TG, Gozani O. ING4 mediates crosstalk between histone H3 K4 trimethylation and H3 acetylation to attenuate cellular transformation. Mol. Cell. 2009; 33:248-256. [PubMed: 19187765]

Jahr S, Hentze H, Englisch S, Hardt D, Fackelmayer FO, Hesch RD, Knippers R. DNA fragments in the blood plasma of cancer patients: quantitations and evidence for their origin from apoptotic and necrotic cells. Cancer Res. 2001; 61:1659-1665. [PubMed: 11245480]

Kakkar VV, Hoppenstead DA, Fareed J, Kadziola Z, Scully M, Nakov R, Breddin HK. Randomized trial of different regimens of heparins and in vivo thrombin generation in acute deep vein thrombosis. Blood. 2002; 99:1965-1970. [PubMed: 11877267]

Lewis S, Mason C, Srna J. Carbon monoxide exposure in blast furnace workers. Aust. J. Public Health. 1992; 16:262-268. [PubMed: 1482718]

Lipinski B, Pretorius E, Oberholzer HM, Van Der Spuy WJ. Iron enhances generation of fibrin fibers in human blood: implications for pathogenesis of stroke. Microsc. Res. Tech. 2012; 75:11851190. [PubMed: 22488824]

Ljungman, P. Doctoral These. 2009. Cardiovascular Effects of Short-term Exposure to Air Pollution : Exploring Potential Pathways and Susceptible Subgroups. (ISBN: 978-91-7409-454-1)

O'donnell MJ, Fang J, Mittleman MA, Kapral MK, Wellenius GA. Fine particulate air pollution $\left(\mathrm{PM}_{2.5}\right)$ and the risk of acute ischemic stroke. Epidemiology. 2011; 22:422-431. [PubMed: 21399501]

Pearce N, Checkoway H, Kriebel D. Bias in occupational epidemiology studies. Occup. Environ. Med. 2007; 64:562-568. [PubMed: 17053019]

Pemberton AD, Brown JK, Inglis NF. Proteomic identification of interactions between histones and plasma proteins: implications for cytoprotection. Proteomics. 2010; 10:1484-1493. [PubMed: 20127695]

Sangani RG, Soukup JM, Ghio AJ. Metals in air pollution particles decrease whole-blood coagulation time. Inhal. Toxicol. 2010; 22:621-626. [PubMed: 20388004]

Seaton A, Macnee W, Donaldson K, Godden D. Particulate air pollution and acute health effects. Lancet. 1995; 345:176-178. [PubMed: 7741860]

Seftel HC. Reactions to intravenous iron Dextran. Br. Med. J. 1965; 1:657. [PubMed: 14245189]

Semeraro N, Ammollo CT, Semeraro F, Colucci M. Sepsis-associated disseminated intravascular coagulation and thromboembolic disease. Mediterr. J. Hematol. Infect. Dis. 2010; 2:e2010024. [PubMed: 21415977]

Siegemund A, Petros S, Siegemund T, Scholz U, Seyfarth HJ, Engelmann L. The endogenous thrombin potential and high levels of coagulation factor VIII, factor IX and factor XI. Blood Coagul. Fibrinolysis. 2004; 15:241-244. [PubMed: 15060420]

Tarantini L, Bonzini M, Apostoli P, Pegoraro V, Bollati V, Marinelli B, Cantone L, Rizzo G, Hou L, Schwartz J, Bertazzi PA, Baccarelli A. Effects of particulate matter on genomic DNA methylation content and iNOS promoter methylation. Environ. Health Perspect. 2009; 117:217-222. [PubMed: 19270791]

Tarantini L, Bonzini M, Tripodi A, Angelici L, Nordio F, Cantone L, Apostoli P, Bertazzi PA, Baccarelli AA. Blood hypomethylation of inflammatory genes mediates the effects of metal-rich airborne pollutants on blood coagulation. Occup. Environ. Med. 2013; 70(6):418-425. http:// dx.doi.org/10.1136/oemed-2012-101079 (Epub 2013 Mar 8). [PubMed: 23476046]

Tripodi A, Martinelli I, Chantarangkul V, Battaglioli T, Clerici M, Mannucci PM. The endogenous thrombin potential and the risk of venous thromboembolism. Thromb. Res. 2007; 121:353-359. [PubMed: 17560633] 
Wielders S, Mukherjee M, Michiels J, Rijkers DT, Cambus JP, Knebel RW, Kakkar V, Hemker HC, Beguin S. The routine determination of the endogenous thrombin potential, first results in different forms of hyper- and hypocoagulability. Thromb. Haemost. 1997; 77:629-636. [PubMed: 9134633]

Wu Z, Liu MC, Liang M, Fu J. Sirt1 protects against thrombomodulin down-regulation and lung coagulation after particulate matter exposure. Blood. 2012; 119:2422-2429. [PubMed: 22262770]

Zhang Z, Chau PY, Lai HK, Wong CM. A review of effects of particulate matter-associated nickel and vanadium species on cardiovascular and respiratory systems. Int. J. Environ. Health Res. 2009; 19:175-185. [PubMed: 20183191] 

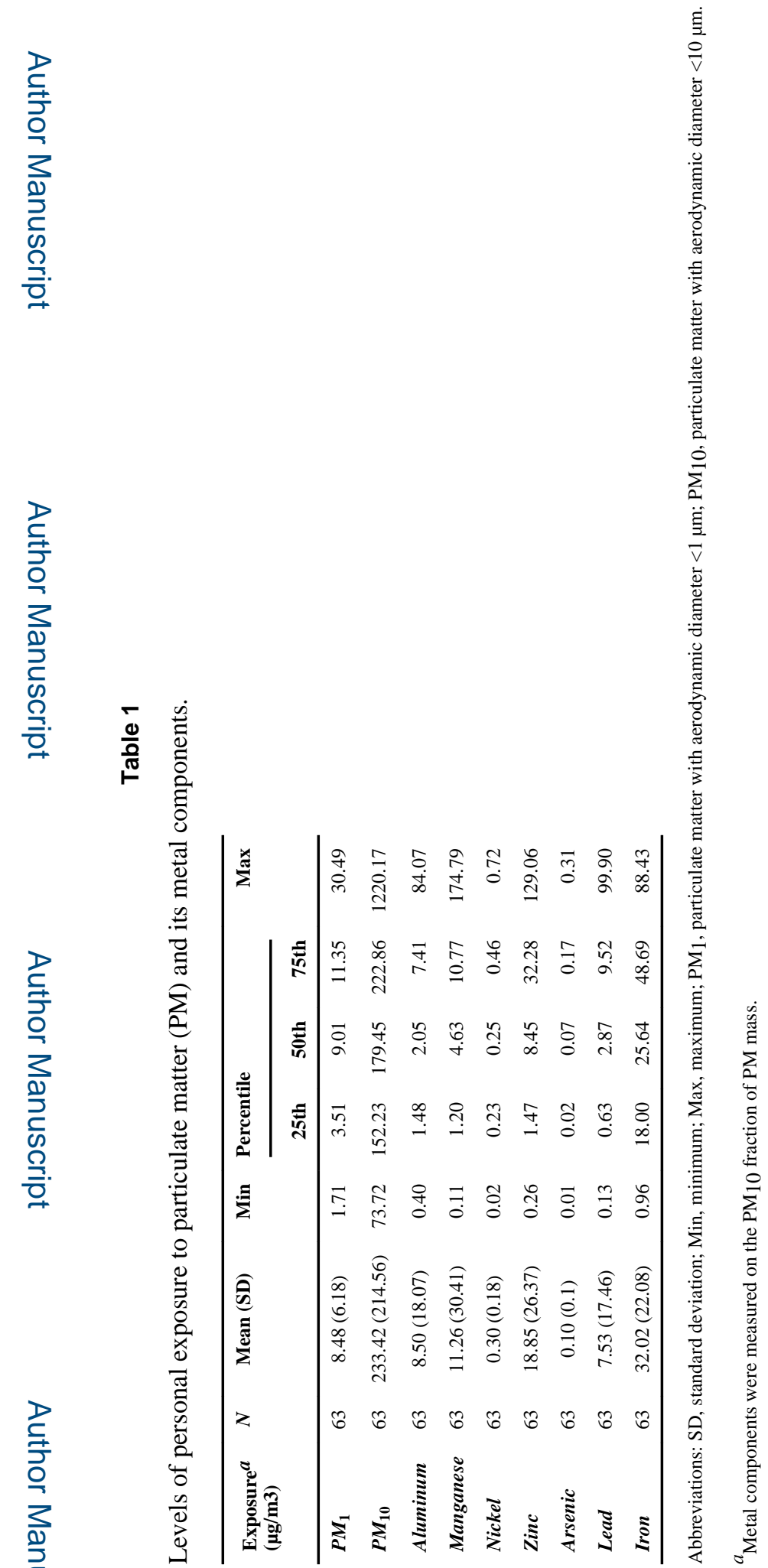

Environ Res. Author manuscript; available in PMC 2015 April 07. 


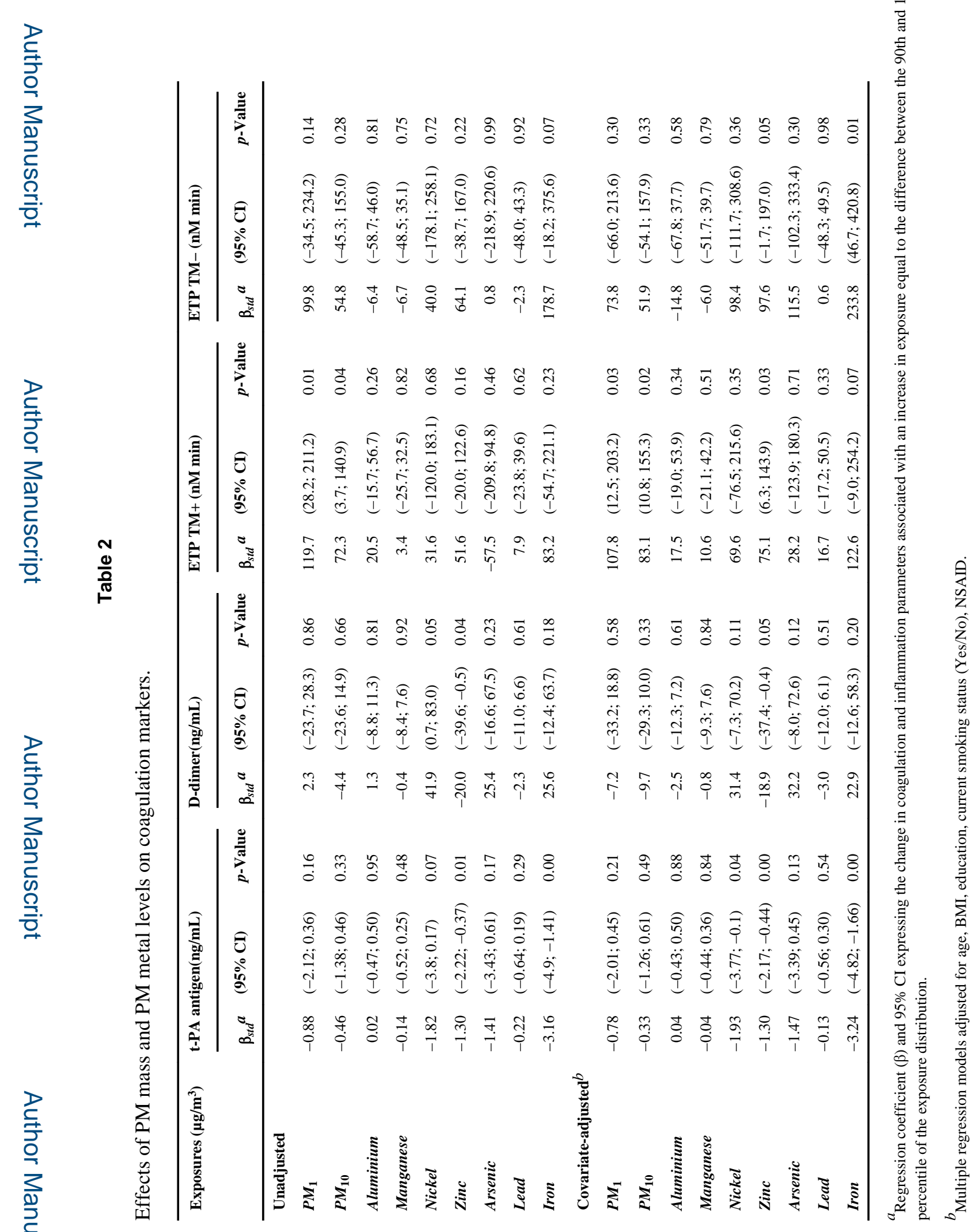

Environ Res. Author manuscript; available in PMC 2015 April 07. 


\section{로을}

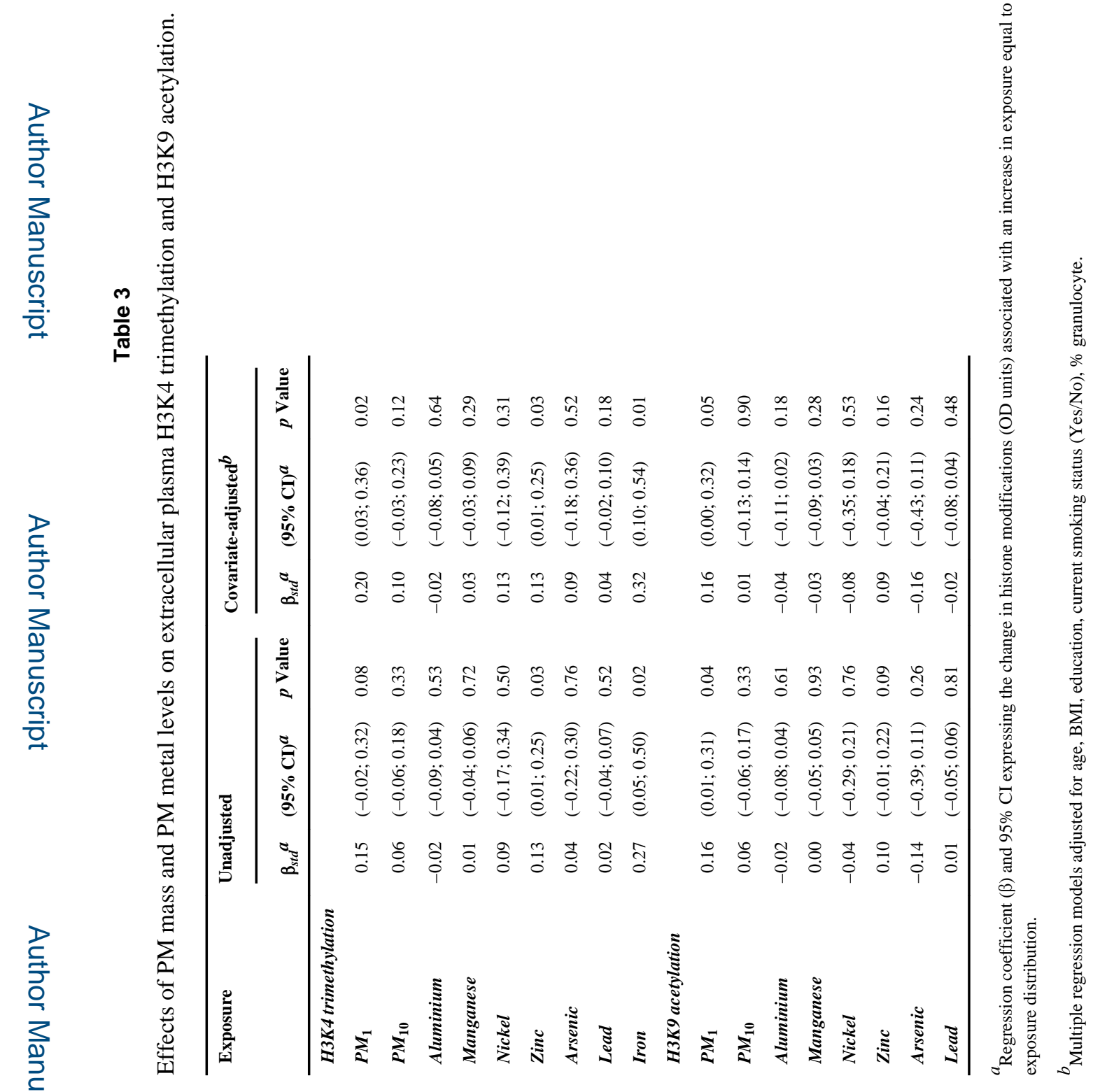

Environ Res. Author manuscript; available in PMC 2015 April 07. 

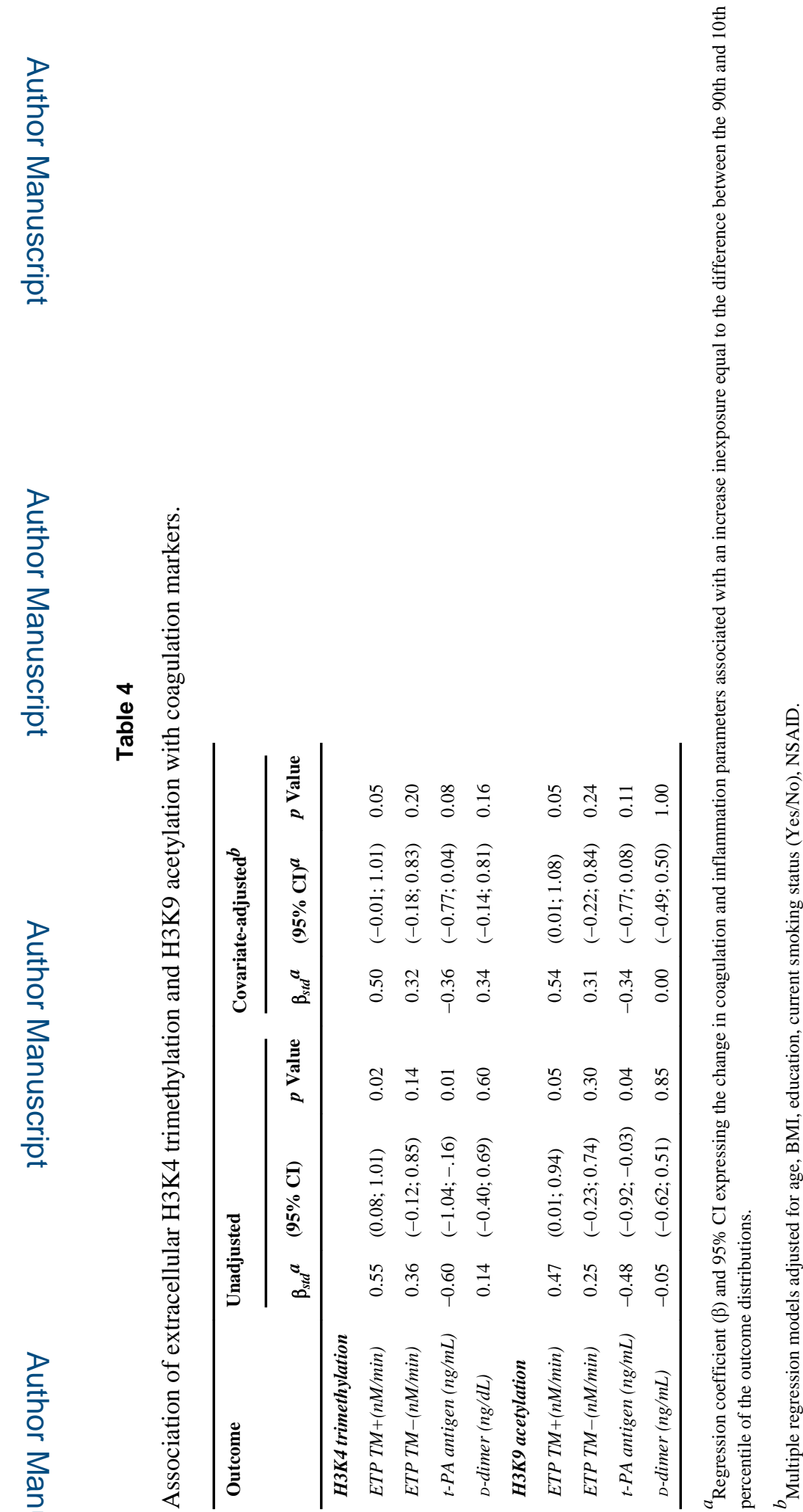

Environ Res. Author manuscript; available in PMC 2015 April 07. 